
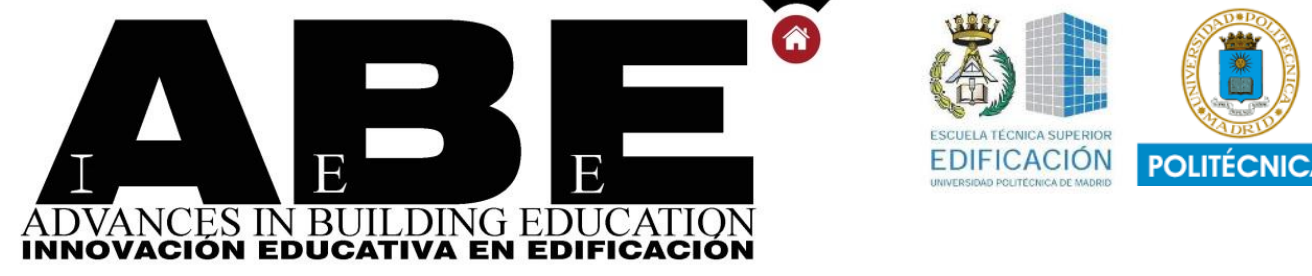

\title{
Polyhedral communication in architecture
}

\author{
Belén Butragueño Díaz-Guerra1; Javier Fco. Raposo Grau'; María Asunción Salgado de la Rosa1 \\ ${ }^{1}$ Department of Graphic Architectural Ideation, School of Architecture of Madrid, UPM
}

Recibido: 22/12/2020 | Aceptado: 10/01/2021 | Fecha de publicación: 15/04/2021

DOI:10.20868/abe.2021.1.4566

\section{ABSTRACT}

There are multiple communicative strategies in architecture depending on the target audience. The mechanisms of representation may radically vary when the recipient is the client, the constructor, the curator, a colleague or even an instructor (1). As an example, the approach may be mainly visual when the target is the client. However, it may be strictly structural to start a conversation with a peer ad mostly conceptual when pointing to the jury members in a competition. In certain cases, the adaptation of the graphic language to the different scenarios leads to such a distortion on the message that the original project is hardly recognizable. To illustrate this point, the article will focus on the project of the Public Seattle Library, designed by the architect Rem Koolhaas. The analysis of five different communicative strategies of the project show peculiar and unequal graphic narrations: from the concept book of the competition, the website of LMN (the American partners of Rem Koolhaas- OMA in this particular project), the website of OMA, the coverage on the Seattle press, the Library Brochure for teenagers and the approach developed on the "Content" book. Rem Koolhaas coined the concept of "design of information" to express the fundamental relationship between the message and media in architecture. In his practice, the communicative strategy is present from the beginning of the design process till the final stages. In this article, the thoughtful comparison of these examples will enable to extract conclusions on the use of communication in architectural design and reflect on the iconic and communicative dimension of architecture in general.

Keywords: Communication, Approach, Information, Design, Analysis. 


\section{INTRODUCTION}

The Seattle Library was a project promoted by the community and, therefore, relying on a very active participation of the people and potential users. In 1998 , the $72 \%$ of the population voted in favor of the implementation of this equipment for the city of Seattle, with the commitment of following a participatory process in all phases, including the design phase. OMA and LMN Architects (local partner) won the competition, over some relevant offices such as Steven Holl or Zimmer Gunsul Frasca.

The process necessarily included consultation sessions with ten different groups (children, teenagers, people with disabilities, elderly, etc.) that made regular contributions that should be taken into consideration. However, the project found some detractors, such as Professor Shannon Mattern (University of Pennsylvania), who believed that the inclusion of the public in the process was merely a communicative strategy (2). She accused Koolhaas of changing the rhetoric of his message according to the audience (community, professionals or the press). She also accused him of using his "celebrity" status to "dazzled" the process.
In our opinion, changing the "rhetoric" or the communicative strategy depending on the audience is not only positive but also necessary, as we firmly believe that it is fundamental to consider actors involved in the communicative act and the importance of the sender, the recipient, the media and the message itself.

With these actions, Rem Koolhaas has actually shown the deep knowledge he has on communicative strategies and the importance he confers to them. This project is paradigmatic in terms of the many communicative approaches that have been developed in different media. It helps us illustrate the way the communicative strategy, the target, and even external circumstances, affect the generation of multiples visions that emerge from a single reality. It is what we call polyhedral communication.

The building has become an icon of the city of Seattle, with its overwhelming presence on the site and its spectacular interiors. They are grandiose, luminous, objectively "spectacular", achieving no residual spaces and that the "in between" ones have that public nature that they are pursuing (Figure 1). 


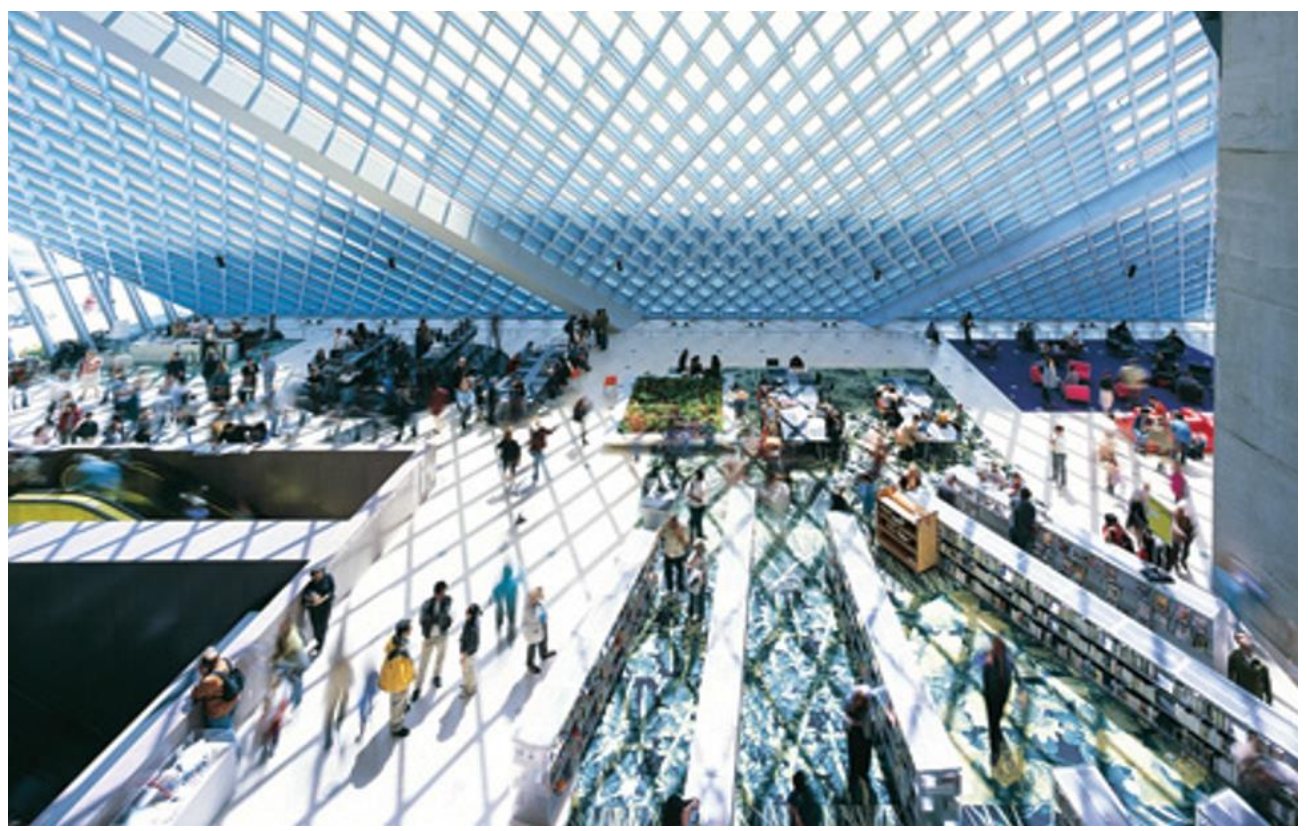

Fig. 1: Interior Image, Seattle Library (Source: OMA)

It was awarded with the first prize of the American Library Association in 2005 and was finalist in the awards "2000-2013 Harvest Crown Hall American Prize". In addition, it obtained the LEED certification of sustainable building, due to the efficient use of resources and materials. In terms of iconography, this project means an anticipation of the CCTV project in Beijing, materializing the concept of" Bigness" and the "iconic" presence (Figure 2).

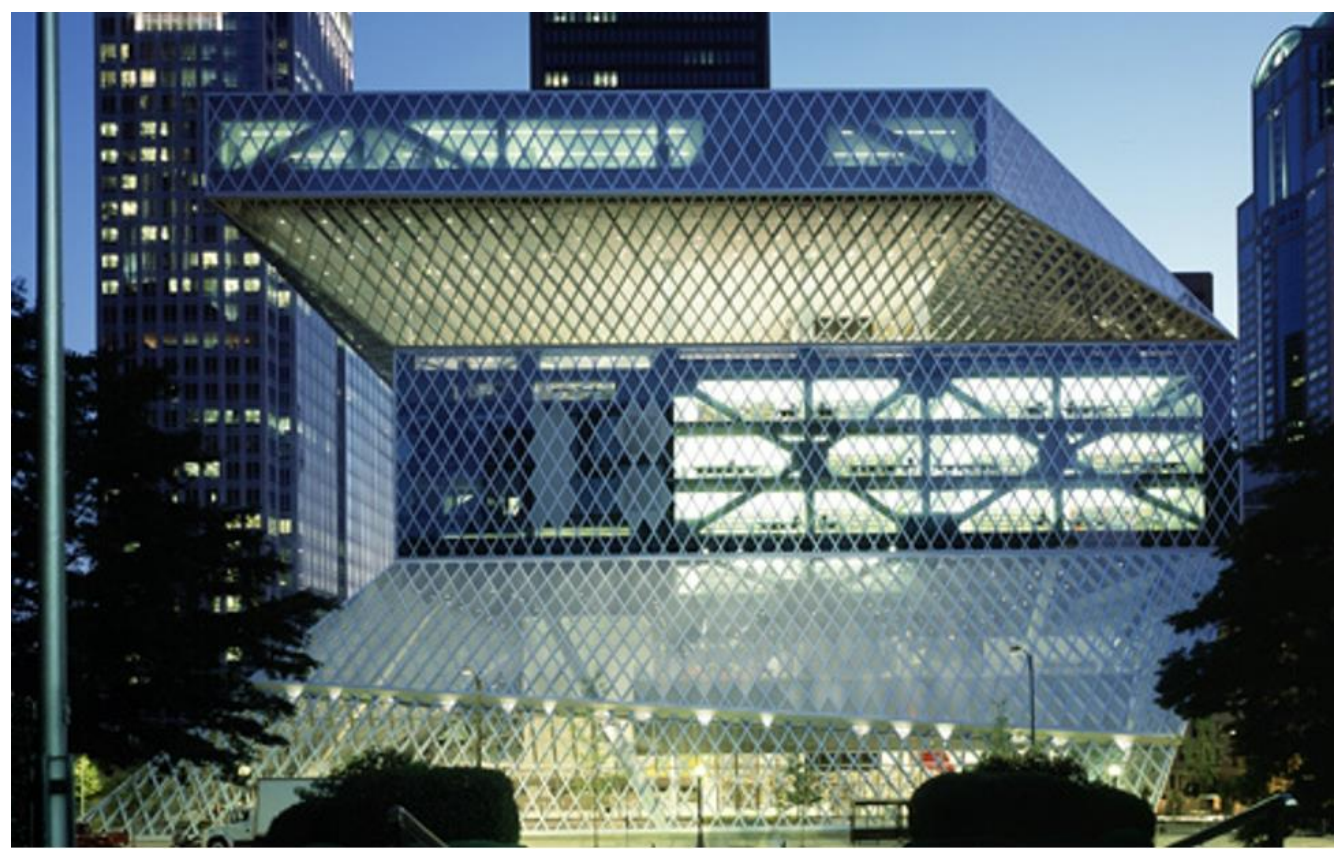

Fig. 2: Exterior Image, Seattle Library (Source: OMA)

Advances in Building Education / Innovación Educativa en Edificación | ISSN: 2530-7940 | http://polired.upm.es/index.php/abe

| Cod. 2101 | Enero - Abril 2021 | Vol. 5 № 1 | pp. 9/22 | 


\section{CONCEPT DESCRIPTION}

Nowadays, libraries around the world are at a crossroad: on one hand, they are a public space, almost the "last bastion of open and free space". Koolhaas defines them as the new "city squares". Therefore, its existence has never been more relevant. On the other hand, the rise of digital media, electronic books, Amazon and Internet are causing its primary mean, the book, to be in a disappearing process. Its existence has never been more questioned.

The challenge is to ensure the suitability of libraries with the present times without losing its essence. "The library represents, maybe with the prison, the last of the uncontested moral universes. The moral goodness of the library is intimately connected to the conceptual value of the book: the library is its fortress; librarians are its guardians..." (3).

In the multimedia world, that guarantees universal access to unfiltered information, it is difficult to find reliable sources. In that context, libraries have become the last fortress and the librarians, brave warriors that try to save "culture" from the barbarian digital world, with a certain moral supremacy.
In addition, this moral superiority and defensive nature is increased by the fact of remaining one of the few loopholes of the public (and not pseudo-public spaces proliferating in the cities) They necessary become homogeneous, nonspecific, generic and enclosed spaces.

The strict program required for the library was approached by OMA's office with flexible diagrams that determined generic and specific spaces. The first diagram seeks to combine and consolidate the ungovernable proliferation of programs and media, instead of turning its back on them. They propose the generation of five areas of "stability" and 4 areas of "instability", a certain abstract machine that is transformed into the Deleuzenian "rhizome".

The areas of stability become very specific programmatic platforms, having each one of them very unique characteristics of size, circulation, flexibility, etc. The spaces between platforms become areas of instability, where interactive and informative exchanges happen, stimulating both work and socialization (Figure 3). The so called "Mixing Chamber" is the main deck, containing the bulk of the collection. Traditionally, libraries have opted for trails 'systems, that generate a very inflexible and unchanging space.
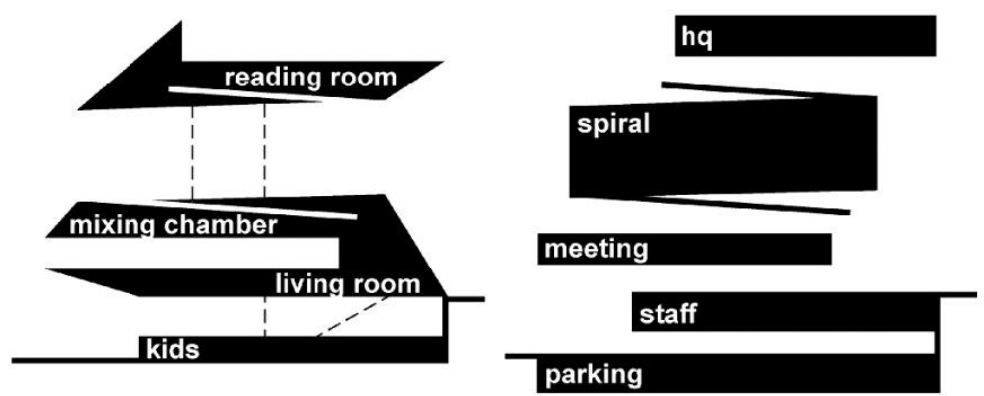

Fig. 3: Programmatic Platforms (Source: OMA) 
That is why OMA opted for a system consisting on a continuous ascending spiral, generating much more connections that a linear system. The librarians have no need to sort and prioritize the massive growth of material. The "mixing chamber" consolidates the same system of accumulative information as the human mind does. The visitor is surrounded by different sources of information, apparently not following a specific order, being the internal connections the ones that generate the logical relationship between them (Figure 4).

\section{TRADITIONAL: \\ LIBRARIAN $=\uparrow$ PATRON $=1$}
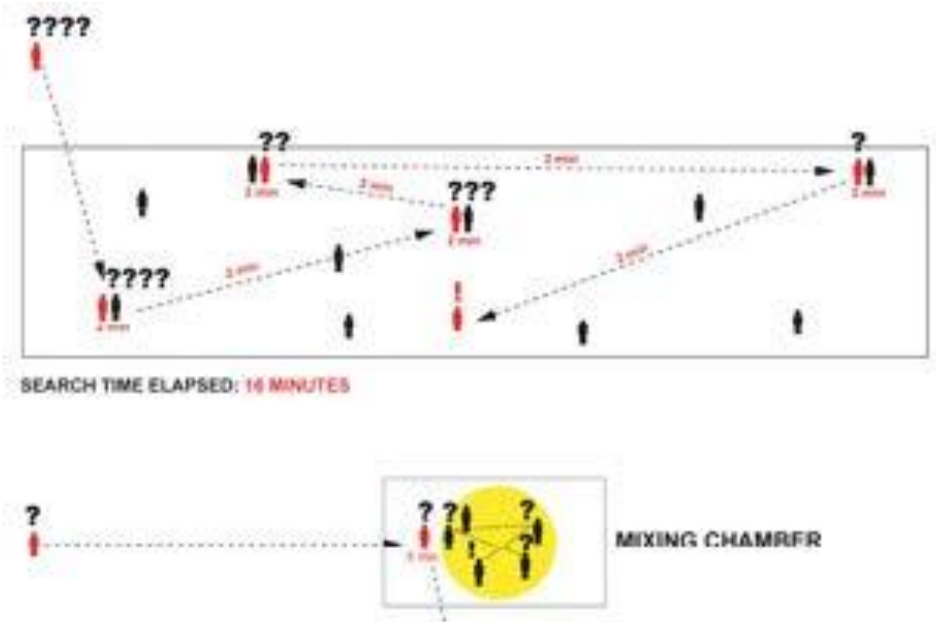

\section{SEATTLE: LIBRARIAN $=1$ PATRON $=1$}

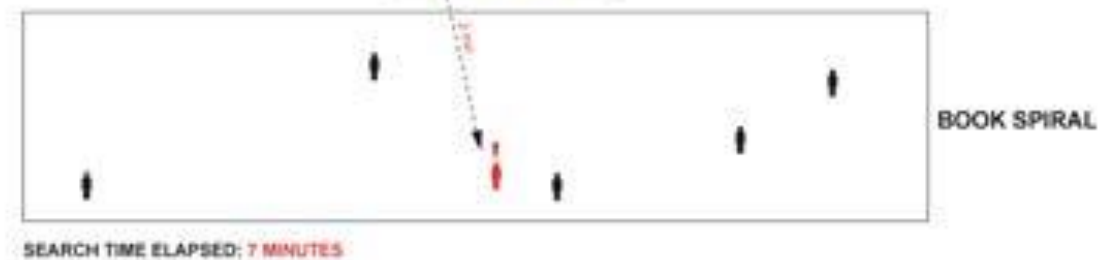

Fig. 4: Traditional Library versus Seattle Library (Source: OMA)

The glass floor reveals the (usually hidden) processes of internal operations in the library, and promotes growth. The capacity of the library at the opening was of 780,000 copies, with the possibility to reach 1.450 .000 books without adding shelves (Figure 5).

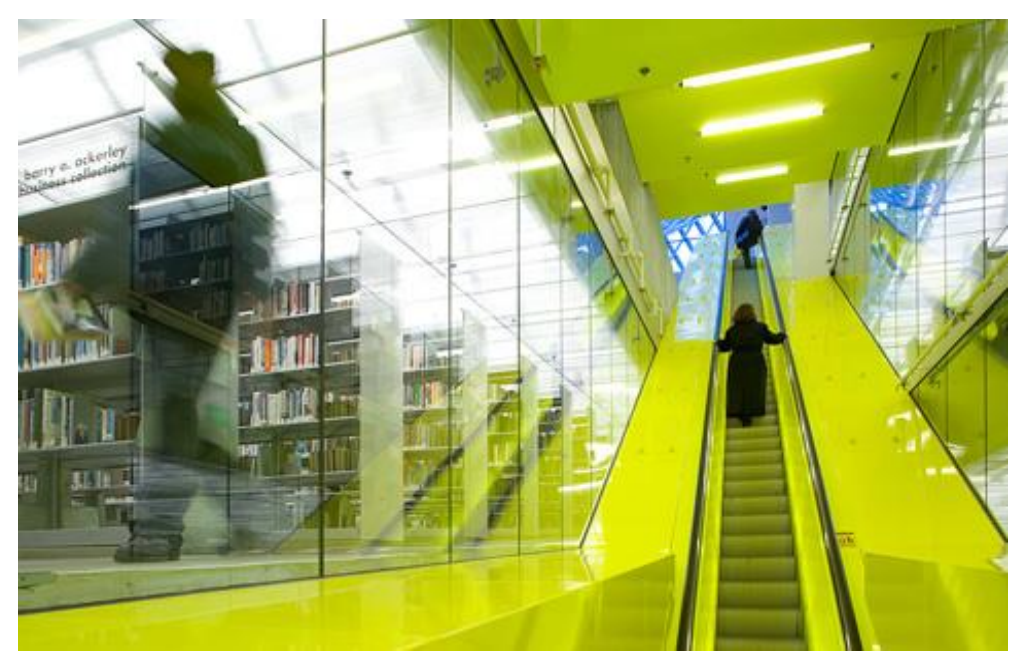

Fig. 5: Mixing Chamber (Source: OMA)

Advances in Building Education / Innovación Educativa en Edificación | ISSN: 2530-7940 | http://polired.upm.es/index.php/abe 
The main quality is the transparency of information. Huge digital screens permanently show the latest books received and requested, the jobs available and messages from internal chat. The booksellers cease to be administrators and become cultural advisers; they go from being "warriors" fighting against the barbarians to teachers "tribe gurus" that provide wisdom (3).

\section{COMMUNICATIVE STRATEGIES.}

In the book "Content", the Seattle Library is illustrated through an article signed by Joshua Prince-Ramus, who was OMA's partner in charge for this project, and was present from design to construction, from OMA's USA office. The book is the first relevant OMA's publication that shows the project after construction. However, the coverage focuses on the design concept, leaving aside constructive solutions, details, materials or building process (Figure 6).

\subsection{Diagrammatic communication: Content Book (2004)}

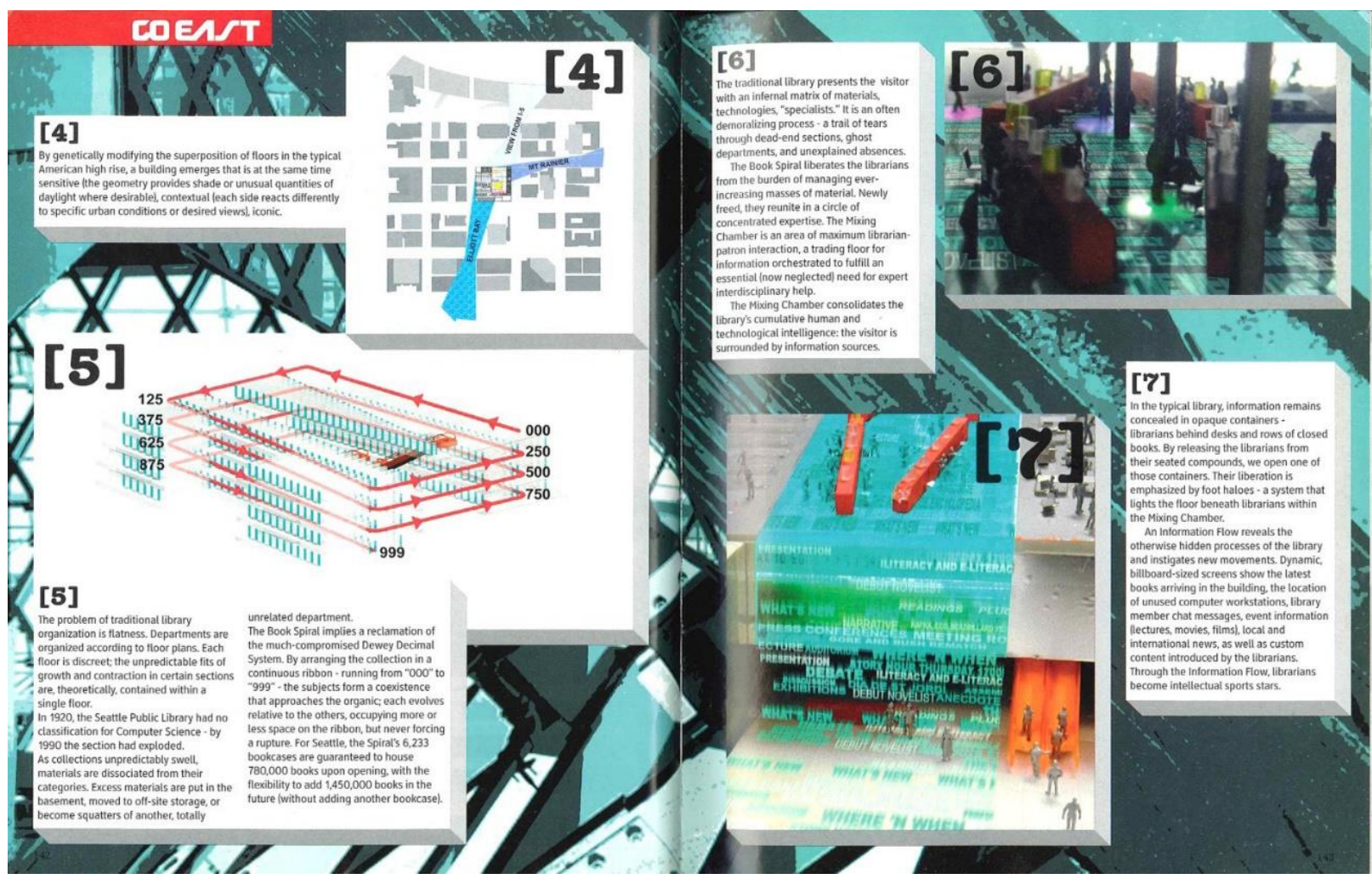

Fig. 6: Project Description on Content Book (Source: OMA)

Surprisingly, the book does not show a single picture of the finished building, elevation, site photos or the exciting interiors. The approximation is specifically and voluntarily atypical. The description focuses on the germinal idea, that questions the real need of libraries nowadays as books' platforms, prevailing its use as a public gathering space (Figure 7). 


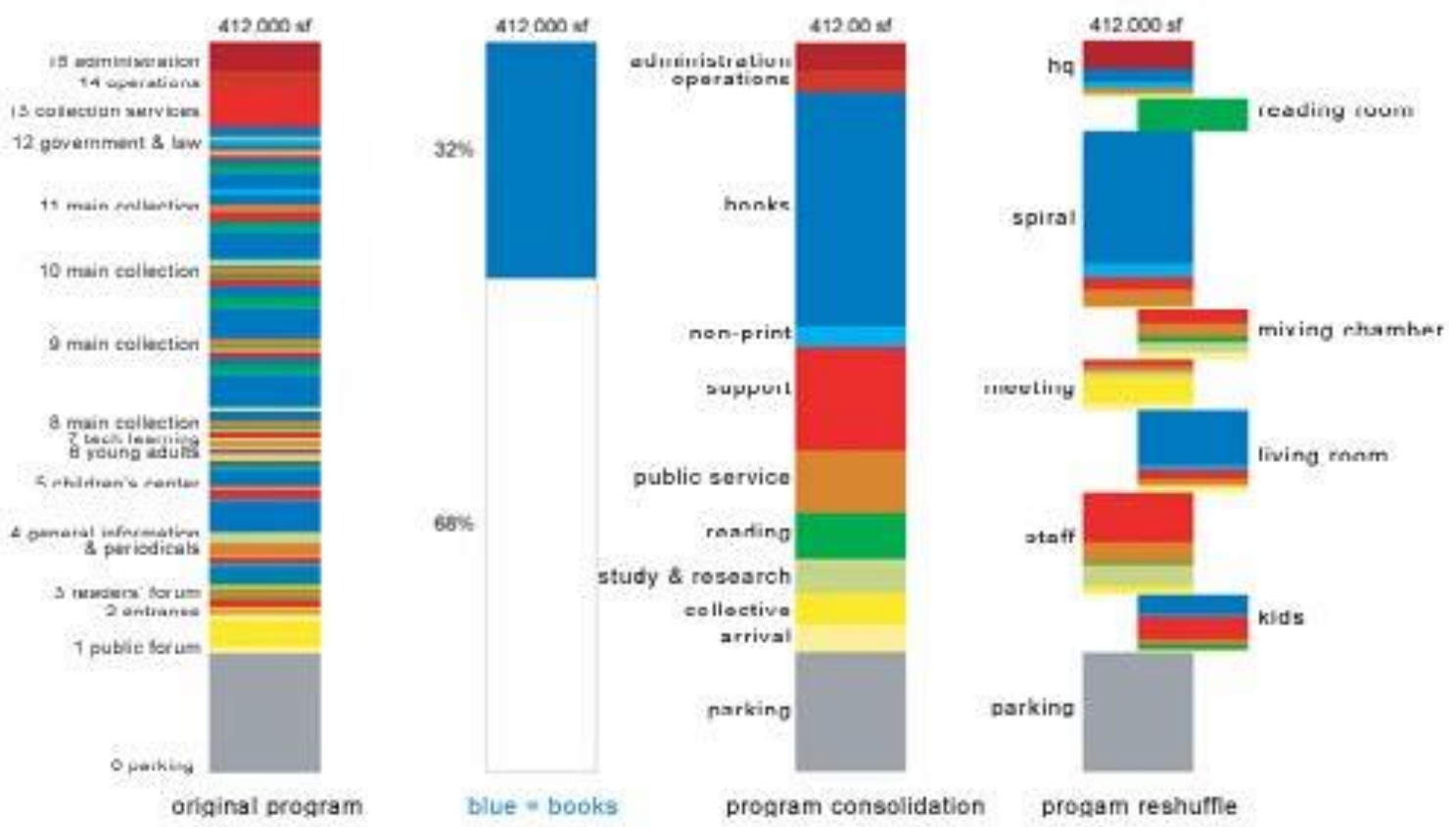

Fig. 7: Conceptual Diagram on Content Book (Source: OMA)

The graphic deployment is based on concept diagrams of the process, focusing on the "mixing chamber", which is the most unique element of the project. The selection of models exposed are very representative as well, as they show workin-progress and not final models. After that introductory text, the book jumps to a description of the constructive and structural drawings, including annotations. In these drawings, the project appears as a dense structural grid, far from the light, transparent appearance of its interiors (Figure 8).

However, there is no trace of the mandatory plans, sections and elevations that are present in conventional architectural monographs.

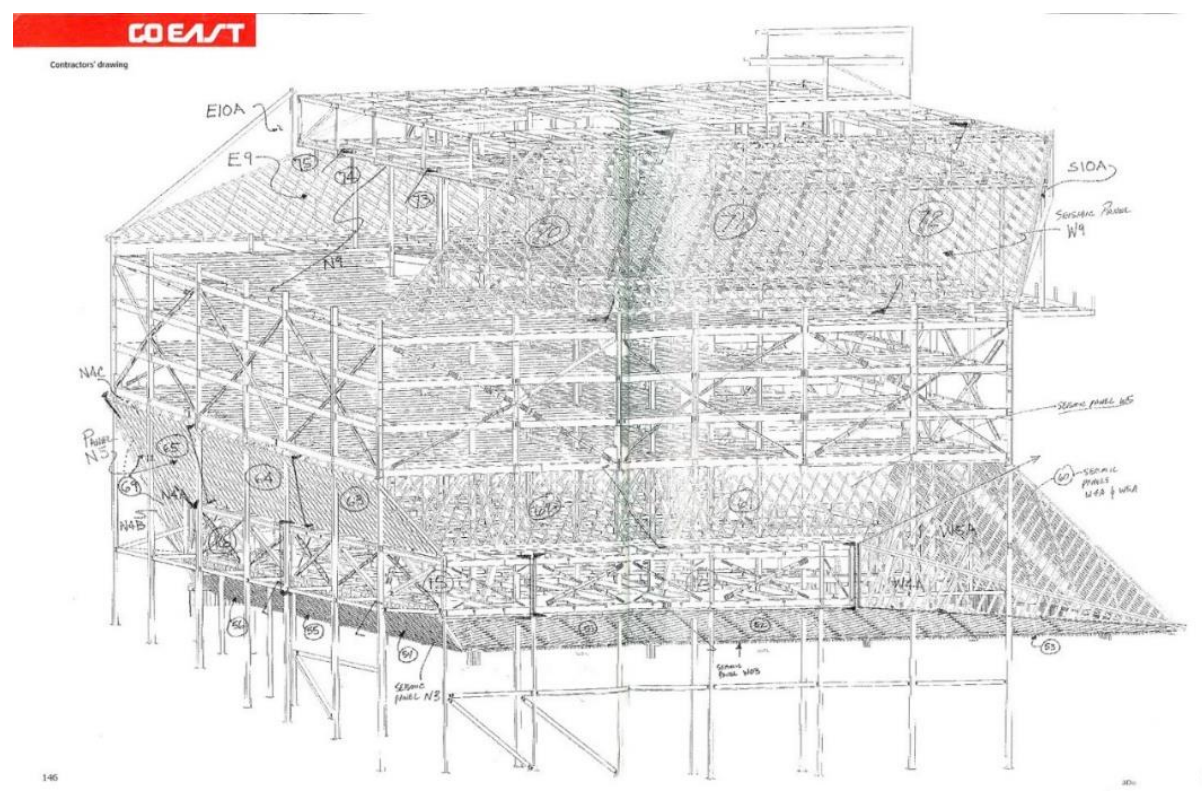

Fig. 8: Structural Diagram on Content Book (Source: OMA)

Advances in Building Education / Innovación Educativa en Edificación | ISSN: 2530-7940 | http://polired.upm.es/index.php/abe

| Cod. 2101 | Enero - Abril 2021 | Vol. 5 № 1 | pp. 9/22 | 
Therefore, the communication of the project is, fundamentally, "diagrammatic" and conceptual. There is no trace of the spectacle, the excitement, and the greatness ("Bigness") expressed by the powerful faceted volume, with a torn geometry. Undoubtedly, the Seattle Library represents OMA's most "iconic" building to date, but that reference is voluntarily avoided in "Content".

\subsection{Persuasive communication: Concept} Book (1999)

The Seattle Library's website offers a link to the initial conceptual proposal presented by OMA and LMN, with Bruce Mau (designer) and Hans Werlemann (OMA's photographer) for the competition's phase. The team's configuration is especially revealing of the importance given to communication in the project, due to the trajectory and relevance of Bruce Mau and his weight in the team.

Throughout its 58 pages, the concept book presented by the original arguments of the proposal. It has a similar aesthetic to the one reflected in the "Content" Book. There are clear aesthetic references to the "Exodus" project (1975) such as the surreal character and the pop culture reminiscences. The main concept is based on a double dichotomy: "public-private" and "analogue-technology" (Figure 9).

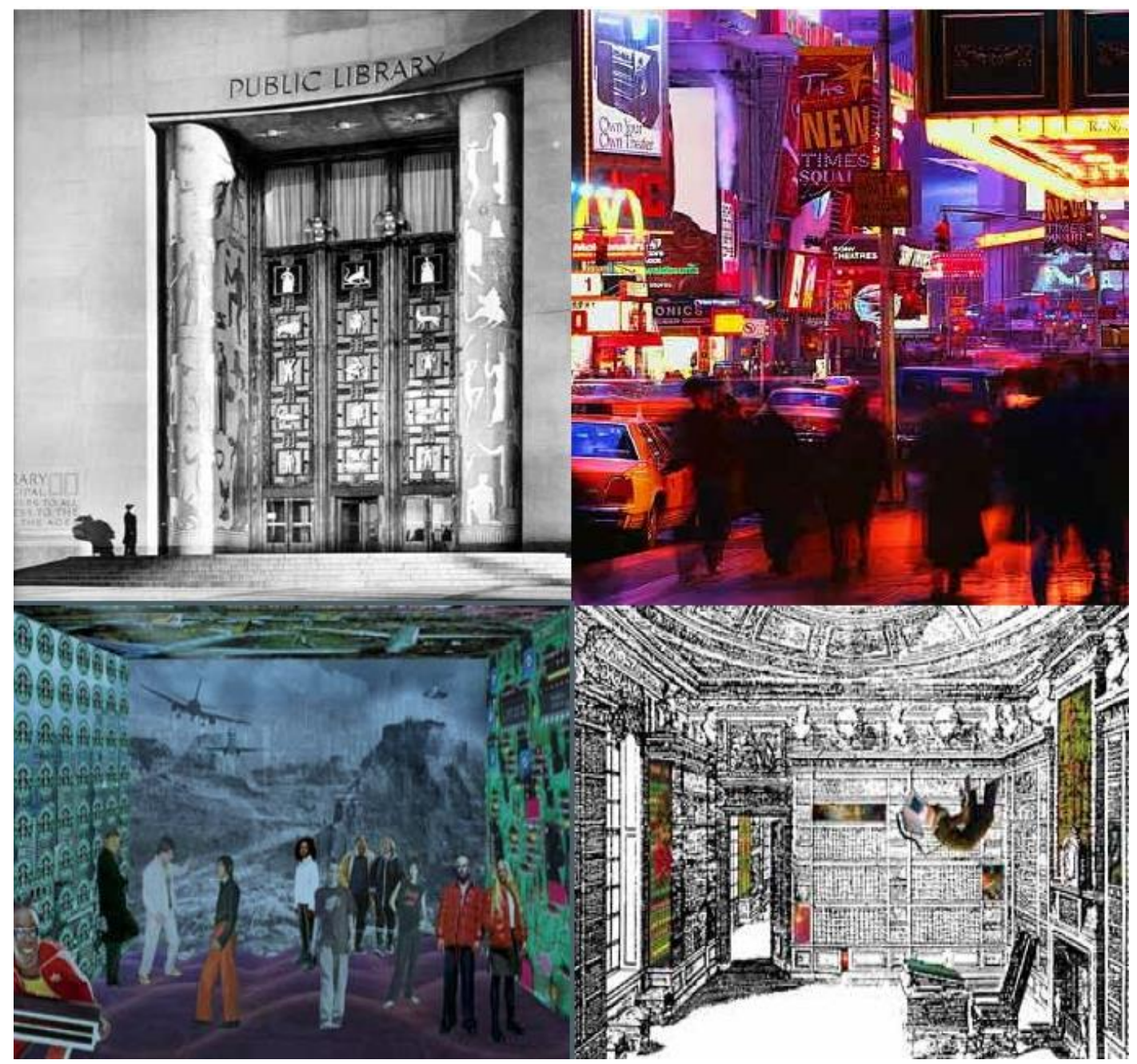

Fig. 9: Diagram on Competition Concept Book (Source: Seattle Library)

Advances in Building Education / Innovación Educativa en Edificación | ISSN: 2530-7940 | http://polired.upm.es/index.php/abe

| Cod. 2101 | Enero - Abril 2021 | Vol. 5 № 1 | pp. 9/22 | 
"Technology is not a threat, but it enables the realization of ancient ambitions - totality, completeness, dissemination, accessibility. In any case, the anticipation of a looming conflict between the real and the virtual is moot at the moment where the two can be made to coincide, become each other's mirror image. The virtual can become the distributed presence of the new Seattle Public Library that users find confirmed in its actual site in the city." (4)
The program presents a flexible configuration by creating specific areas whose use may vary and expand. The proposal is to create a balance between the traditional functions of a library and the growing proliferation of new technologies and audio-visual media. The aim is to generate a space that reflects the emerging cultural environment of the city (Figure 10).

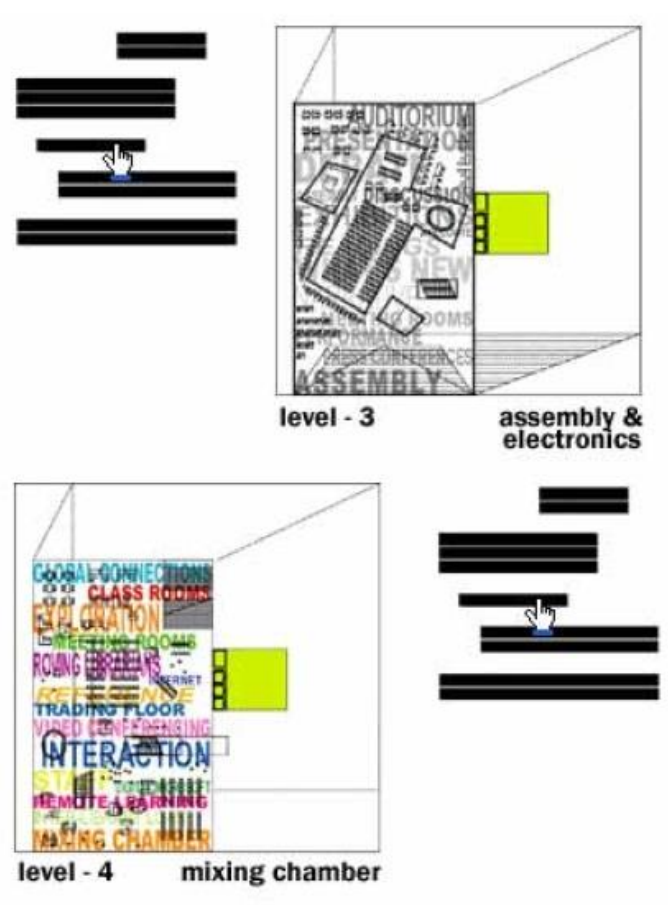

Fig. 10: Diagram on Competition Concept Book (Source: Seattle Library)

The faceted envelop responds to the optimum arrangement of the platforms and the search for the best lighting and environmental conditions in each case. It's also a symbol of a time characterized by the iconic architecture; a representation of a new modernity opened in Seattle by Frank Gehry's Museum of Pop Culture (2000).

\subsection{Commercial communication: LMN} Architecture (2002)
It was the first collaboration among LMN Architects and OMA, but the office had previously worked with some other "Star System" architects, such as Frank Gehry, in the Museum of Pop Culture, also in Seattle.

The coverage of the project displayed on their website, could be described as canonical. It includes the most spectacular photos of interiors and exteriors, a site referential plan, floor plans, elevations, sections and all kind of details (Figure 11). 


\section{ᄂmח}

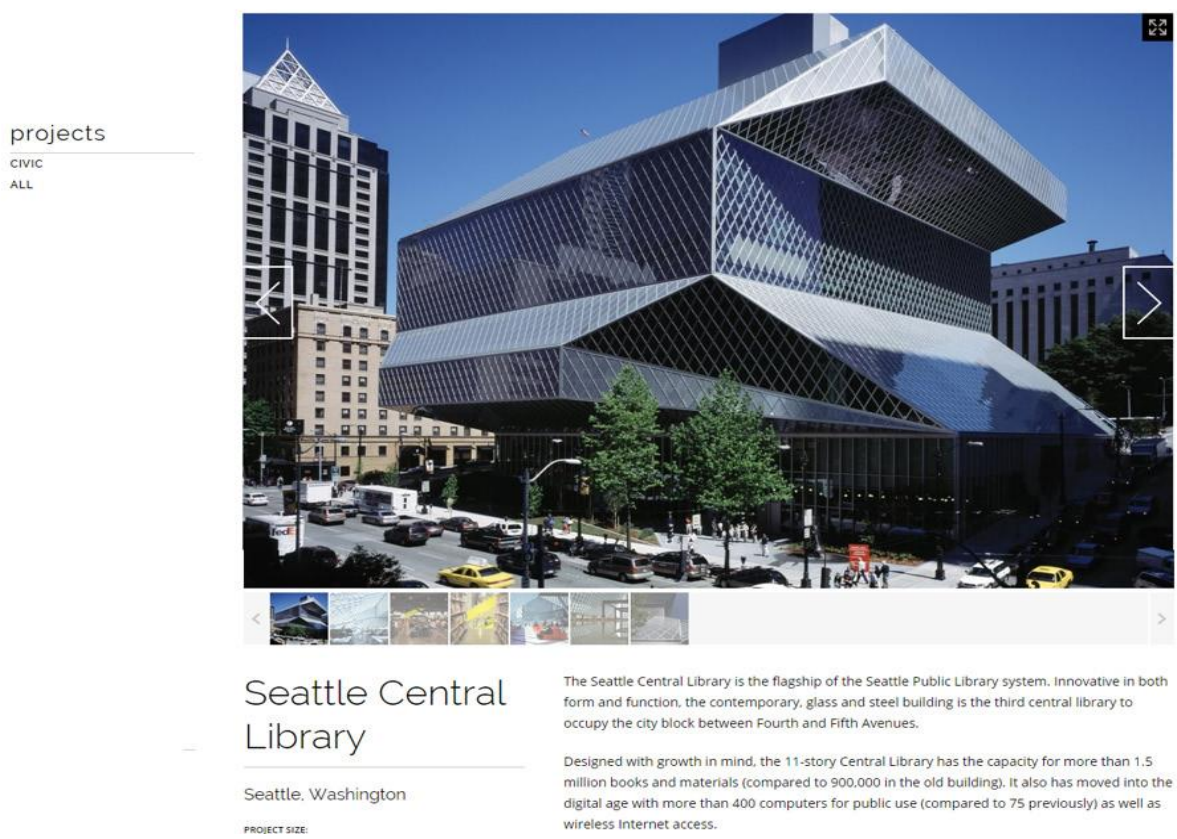

Fig. 11: LMN Architects Webpage (Source: LMN Architects)

It also provides an enormous amount of quantitative data, such as dimensions, books' capacity, number of computers, budget, prizes and awards, certificates, and so on. However, it gives a succinct information about the concept which, in addition, it is not exactly coincident with OMA's:

"The design objective, by Rem Koolhaas and Joshua Ramus, in partnership with LMN, was to create a building that honors books, and at same time, is very forward-looking to reflect major technological advances in the information business." (5)
Definitely, the website deploys a complete description of the building, following a linear narration from a commercial perspective.

\subsection{Anatomic communication: Press coverage}

The Seattle Press offered a graphic information of the project from a pedagogic approach. Using a deployed section oblique, the drawing works as an anatomic dissection of the different parts that conform the project, from the skin, to the skeleton to the "body" organs (or functions) (Figure 12). 


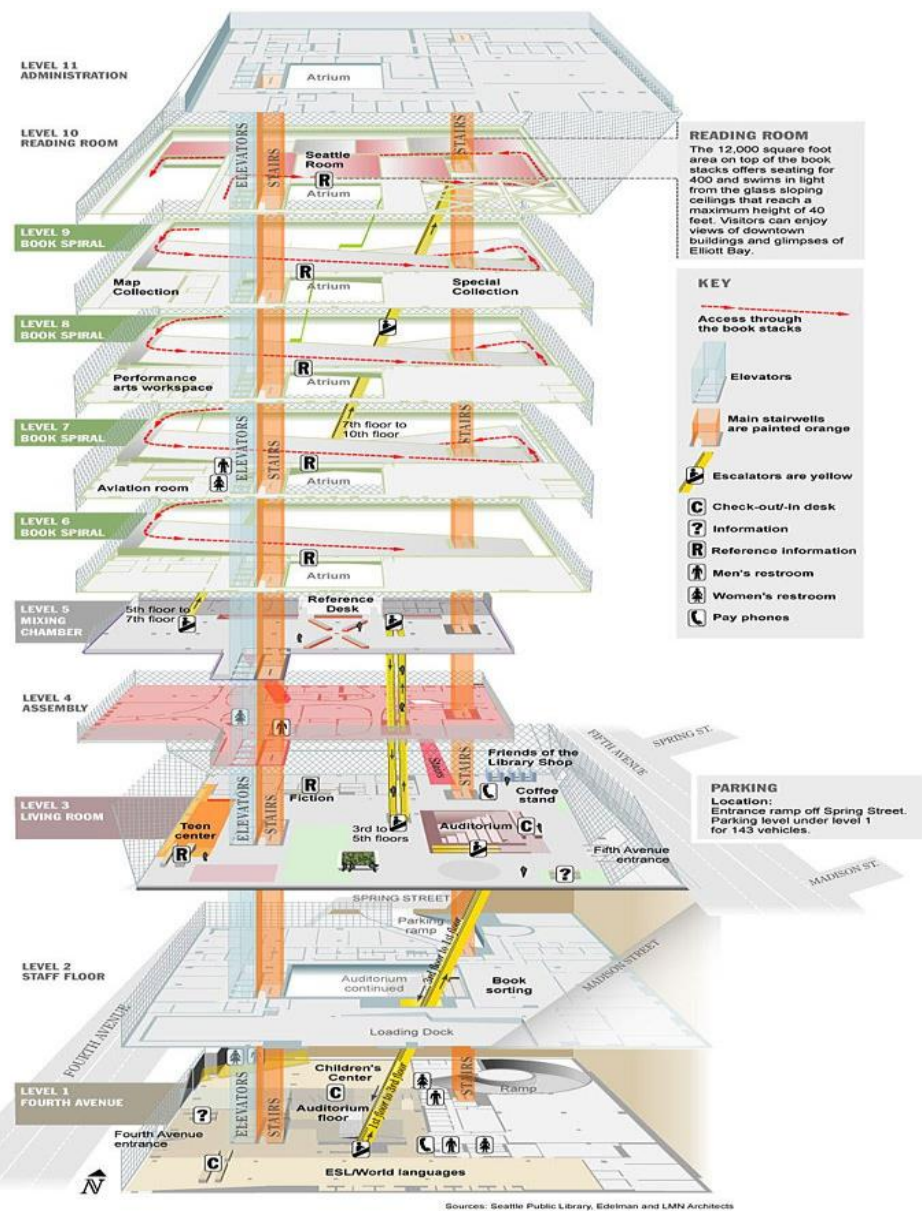

Fig. 12: Diagram in Seattle Press (Source Seattle Press).

The disengagement of the different levels generated to illustrate the programmatic content, causes a complete distortion of the volume, which is one of the most recognizable elements of the project.

Other fundamental qualities, such as the light, the transparency and the great open spaces are diluted under this parameter.

\subsection{Pragmatic communication: Library} Brochure (2016)
To perform a full scan of the different communicative strategies affecting this project, it is interesting to analyze the Library's brochure designed explicitly to attract the younger users. The intention of this document is to help users to find the different designated areas, including the mixing chamber, consulting areas, study rooms, children areas or restrooms with an engaging design (Figure 13). 


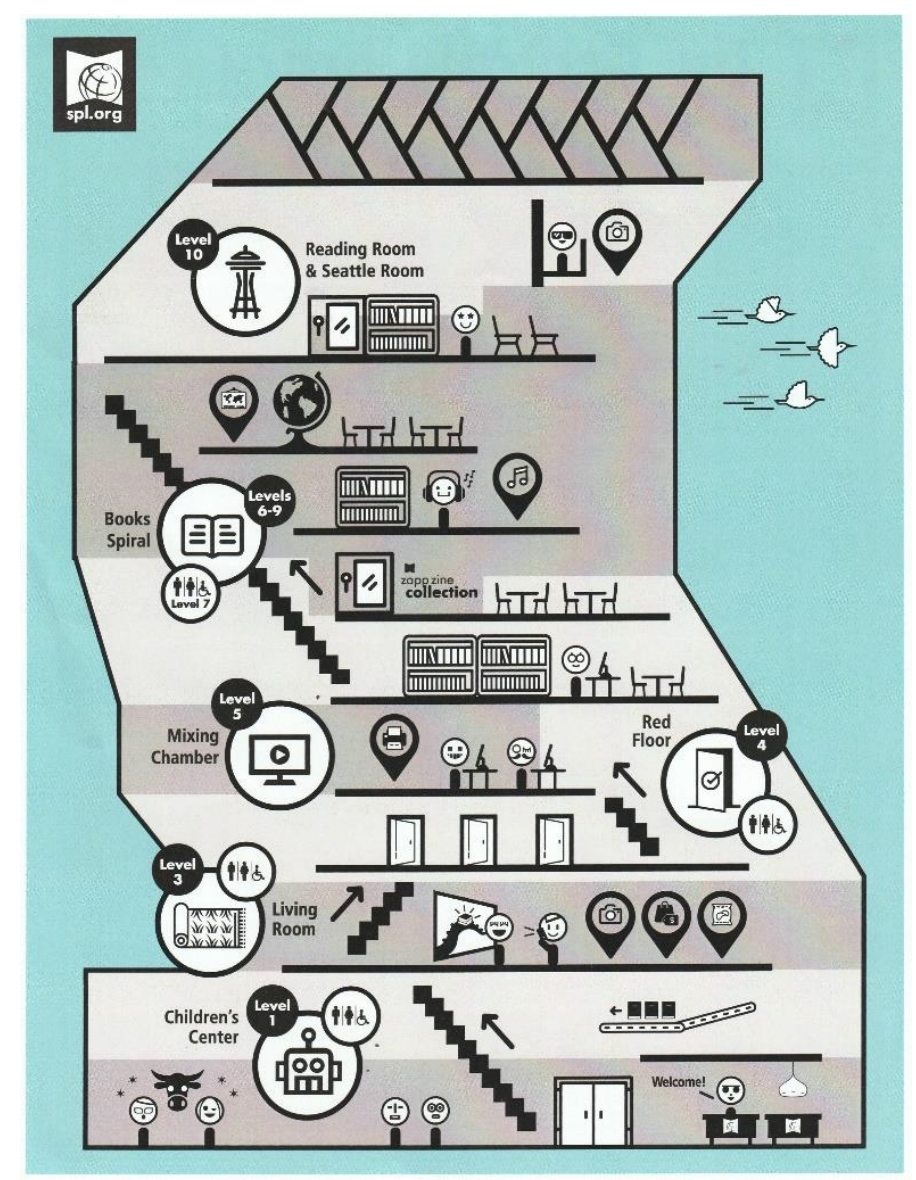

Fig. 13: Seattle Library Brochure for Teens (Source: Seattle Library)

The graphic language is based on the pictogram, it emerges from the simplification and even the deformation of shapes and proportions, to make the drawing readable for a very specific target, away from rigorous representations. The comic aesthetic pretends to engage with teenagers and awake a sense of belonging to the library community.

\section{CONCLUSIONS}

The Seattle Library sets a perfect example on how the adaptation of the graphic language to a variety of narrative styles and targets, generates such different representations of the object, that the project is hardly recognizable. The narrative descriptions may even be antagonistic (Figure 14). This project meant a breakthrough in the field of architectural communication. The strategies followed not only to represent, but also to defined the project in the different stages, were decisive for the further success of the building. The active efforts of involving civil society in the decision-making process, ensured that the people adopted the building as their own, creating a sense of belonging and transforming the iconic imaginary perception of the city (6). Just by walking around the different floors, it can be noted how the building is responding to the needs of widely differing user profiles. The communicative process developed was bidirectional; Rem Koolhaas and his team didn't just present the proposal to the different 
entities: users, public institutions, co-designers, constructors... They listened to their concerns and suggestions and incorporated them to improve the design.
This project sets an example of collaborative work, where communication is at the core of the design strategy, to the point that they become merging concepts.

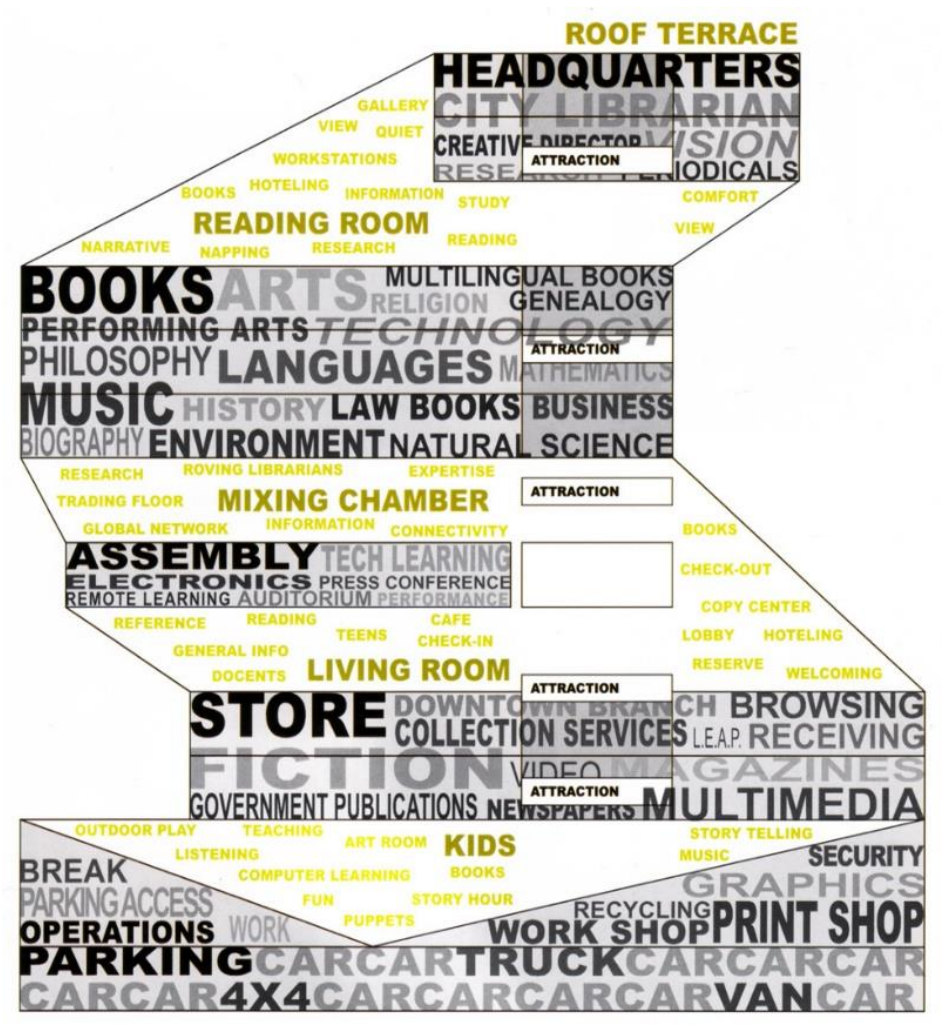

Fig. 14: Functional Diagram (Source: OMA)

Koolhaas uses the concept "design of information" to point out the importance of both the message and media, which are interdependent, in this case. The methodology developed to transmit the information may affect the information itself. OMA considers that the communicative strategy should be present from the very beginning of the process of architectural design and remain during the different stages.

Going a step further, it would be possible to use the "design of information" as a designing tool itself. The interpretation of a project under the prism of a different graphic strategy may generate a completely new project. This is exactly what happens in the Seattle Library, where the design-communicative program tries to respond to the most important questions of any project nowadays: what is the main objective to fulfil, how is it going to be implemented and who is the target audience. (7)

Rem Koolhaas and OMA are a representative example of mastering the communication in architecture, but this resource is not exclusive to the world of architecture, it extends to many other creative fields, where communication plays a fundamental role. 


\section{REFERENCES}

[1] G. Bateson, "Steps to an Ecology of Mind", Jason Aronson Inc., San Francisco, 1972.

[2] Shannon Matter, How Public Is the Seattle Public Library? Publicity, Posturing, and Politics in Public Design". Journal of Architectural Education, Vol. 57, No. 1 (Sep., 2003): 5-18.

[3] OMA, R. Koolhaas, "Seattle Public" in Content, Germany, Taschen, 2004, 138-149

[4] Seattle Public Library. "Concept Book for the New Central Library". Accessed May 1, 2016. http://www.spl.org/locations/centrallibrary/cenbuilding-facts/cen-omalmnconceptbook

[5] LMN Architects. "Seattle Public Library". Accessed May 1, 2016.

http://Imnarchitects.com/project/seattlecentrallibrary

[6] R. Venturi, S. Izenour, D. Scott Brown, "Aprendiendo de Las Vegas (El simbolismo olvidado de la forma arquitectónica)". Barcelona: G. Gili, 1978.

[7] B. Butragueño, "Rem a los dos lados del espejo", PhD diss., Polytechnic University of Madrid, 2015 